\title{
Implementation Science in Suicide Prevention
}

\author{
Lennart Reifels ${ }^{1}$, Sadhvi Krishnamoorthy², \\ Kairi Kõlves ${ }^{2,3}$, and Jillian Francis ${ }^{4,5,6}$
}

${ }^{1}$ Centre for Mental Health, Melbourne School of Population and Global Health, The University of Melbourne, VIC, Australia

${ }^{2}$ Australian Institute for Suicide Research and Prevention, Griffith University,
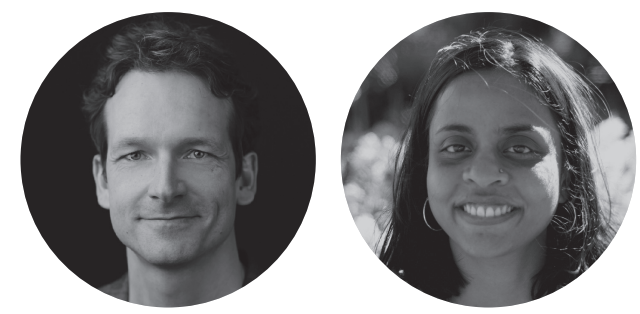

Mount Gravatt, QLD, Australia

${ }^{3}$ WHO Collaborating Centre for Research and Training in Suicide Prevention,

School of Applied Psychology, Griffith University, Brisbane, QLD, Australia

${ }^{4}$ School of Health Sciences, The University of Melbourne, VIC, Australia

${ }^{5}$ Department of Health Services Research, Peter MacCallum Cancer Centre, Melbourne, VIC, Australia

${ }^{6}$ Clinical Epidemiology Program, Ottawa Hospital Research Institute, Ottawa, ON, Canada

The suicidal process is a complex phenomenon involving multiple intertwined factors, which makes its prevention particularly challenging. As evidence-based suicide prevention interventions evolve and consolidate, it becomes increasingly important to ensure that effective interventions are efficiently implemented in practice and translated into the quality programs and care that benefit people at risk of suicidal behavior.

Implementation science has been defined as, "the study of methods to promote the systematic uptake of evidence-based interventions into practice and policy to improve health" (Wolfenden et al., 2021, p. 1). Implementation science has been a buzzword in the broader health and medical fields for about two decades and is increasingly gaining traction in suicide prevention. The recent release of the World Health Organization (WHO) Live Life: Implementation Guide for Suicide Prevention in Countries (WHO, 2021) provides a major global and national policy impetus to harness the rich arsenal of implementation science to foster implementation research and practice in suicide prevention.

The explicit adoption of implementation science frameworks and concepts is a relatively recent but rapidly increasing phenomenon in suicide prevention. Yet, key aspects of relevance to the implementation of complex interventions have long been a focus under various other traditions (such as process and formative evaluation, health services research, quality improvement, dissemination or translational research), upon which we can build and expand (Bauer et al., 2015; Graham et al., 2006; Zbukvic et al., 2020).
In view of this, the aims of this editorial are threefold. We seek to (1) highlight the merit of implementation science for suicide prevention research and practice; (2) outline key implementation science concepts and approaches to foster future research and establish the evidence base for effective implementation in suicide prevention; and (3) illustrate applications and key considerations for implementation science approaches in diverse contexts (using examples of multilevel interventions).

\section{Understanding Evidence-Practice and Quality-of-Care Gaps}

Although the effectiveness of interventions remains variable and is hard to compare across the spectrum of universal, selective, and indicated interventions and settings (Mann et al., 2021), real-world decisions to implement suicide prevention programs and services are rarely driven only by the evidence base. Decisions are frequently informed by population needs, equity considerations, or available resources or they are motivated by policy priorities, funding opportunities, innovation potential, or the prevailing ethos of care. As such, suicide prevention across countries may involve a range of programs, support services, and interventions, which exist side by side with varying quality and alignment to evidence-based practice.

In this context, it therefore becomes important to carefully appraise evidence-practice and quality-of-care gaps 
in suicide prevention, which are also considered near ubiquitous in healthcare (Schuster et al., 1998; Shrank et al., 2019). It is thus critical to understand not only which suicide prevention programs and interventions are currently being implemented, but also how well these are implemented, and with what evidence of effectiveness. It is conceivable that interventions that are known to be highly effective can be delivered rather poorly or brilliantly in practice. Similarly, interventions that are largely ineffective (or perhaps even contraindicated) can also be well resourced and implemented (Levinson et al., 2015). In each case, this will have direct ramifications for the resulting quality and potency of interventions (Kapur et al., 2021). Evidence-practice gaps can manifest in many forms, including slow or no uptake of interventions that are already known or shown to be effective, or the delivery of low-value care that provides little benefit or may in some instances even be harmful. However, the absence of evidence on certain interventions should not have a paralyzing effect on practice. Considering persistently high suicide rates worldwide, there is a need for research on innovative and promising interventions that are both effective and implementable in routine practice. However, ongoing evaluation of interventions, even after implementation, is vital so as to avoid persistent low-value practice in suicide prevention (Pirkis \& Hawton, 2021).

\section{Key Concepts: Implementation Strategies, Frameworks, and Outcomes}

Implementation strategies are the critical know-how component of practice change and have been defined as the specific "methods or techniques used to enhance the adoption, implementation, and sustainability of a clinical program or practice" (Proctor et al., 2013, p. 2). Implementation strategies can include varied top-down, bottom-up, or push-pull strategies, which facilitate implementation through mechanisms such as planning, education, finance, restructuring, quality management, policy measures, or behavior change techniques. While implementation science has frequently focused on fostering the implementation of clinical interventions in healthcare settings, implementation strategies in the context of suicide prevention can be applied to the broader gamut of universal, selective, and indicated interventions that are delivered across a range of contexts.

The Expert Recommendations for Implementing Change (ERIC) study established and defined a comprehensive list of 73 discrete implementation strategies, which can be used to inform implementation research and practice and to construct multifaceted strategies that facilitate implementation in complex real-world practice scenarios (Powell et al., 2015). Evidence about the effectiveness of implementation strategies is frequently synthesized by the Cochrane Effective Practice and Organization of Care (EPOC) group (https://epoc.cochrane.org/). Yet, despite advances in our understanding of effective implementation strategies for mental health interventions (Powell et al., 2014), systematic reviews and knowledge about effective implementation strategies within the suicide prevention field are still largely missing today, signaling an important research gap to be addressed.

One of the advantages of implementation science approaches is the use of theoretical frameworks and models that explicitly seek to specify and foster a greater understanding of what works for whom, where, when, and why, and under which circumstances (Damschroder et al., 2009). A review by Tabak et al. (2012) identified 61 models and frameworks used in implementation research, which capture varying aspects and determinants of the implementation process and environment (Nilsen, 2015). Among the more commonly used frameworks are the Consolidated Framework for Implementation Science (Damschroder et al., 2009; https://cfirguide.org/), Proctor's conceptual model for implementation research (Proctor et al., 2009), and designated behavior change frameworks, such as the taxonomy of behavior change techniques (Michie et al., 2013).

It is always important to evaluate implementation strategies, rather than assuming they will be effective. According to Proctor et al. (2011), the success of implementation processes (as distinct from service system or client outcomes) can be conceptualized and measured in terms of key outcomes such as acceptability, adoption, appropriateness, costs, feasibility, fidelity, penetration, or sustainability. As a rule of thumb, studies may qualify as implementation research if: research participants are involved in the delivery or implementation of an intervention; the problem to be addressed concerns the quality or efficiency of delivery; the research question involves identifying, investigating, or addressing evidence-practice or quality-of-care gaps; and the ultimate aim is to build evidence about whether implementation strategies work.

\section{Exploring and Addressing Barriers and Enablers of Practice Change}

Policy changes at the organizational or system levels (topdown approaches) are often seen as the starting point for implementation (While et al., 2012). However, it would 
be naïve to assume that these initiatives result in immediate, consistent, and high-quality delivery of interventions in practice. To complement the top-down initiatives, bottom-up approaches investigate the contextual, team- and provider-level barriers and enablers to practice change, aiming to identify solutions to support high-quality evidence-based implementation and delivery of interventions. Within this approach (proposed by French et al., 2012), the first step is to specify precisely who needs to do what, differently, to deliver the intervention to a target group (i.e., people at risk of suicide). In practice, creating consensus at this step is more difficult than it may at first seem. The Action, Actor, Context, Target, Time (AACTT) framework (Presseau et al., 2019) is a worksheet-based tool to facilitate decisions among healthcare teams and managers in relation to these five elements, which can be applied to the implementation of any suicide prevention intervention. Importantly, deciding the Actor component of the framework is then used to identify key intervention providers and stakeholders who should be consulted in the next step of an implementation project.

Having identified providers and informants, the second step is to contextualize the implementation problem by identifying the barriers and enablers, in the contexts and at the times identified in Step 1. The Theoretical Domains Framework (TDF) of behavior change (Michie et al., 2005; Cane et al., 2012) provides a basis for a conversation, discussion, or interview with key informants about the barriers and enablers to performing those AACTT-specified behaviors. This step is important so that a solution can be chosen to match the nature of the problem. For example, if there is a knowledge deficit among practitioners, which explains why they are not delivering an effective intervention, then an educational implementation strategy is appropriate. However, many care gaps arise from other types of barriers. For example (to exemplify other theoretical domains), providers may lack confidence in their ability to deliver the intervention effectively; may find that the client's emotional state makes it difficult for them; may feel that it is outside their professional role to deliver a specific kind of intervention; or that they have insufficient resources such as time, or insufficient support from their colleagues. If these are the key barriers to performance, practitioner education alone is unlikely to support practice change. Other types of implementation strategies could therefore provide a better fit with the identified source of the evidence-practice or care gap.

\section{Key Considerations for Implementation Research in Suicide Prevention}

Suicide prevention interventions vary in degree of complexity and include multifaceted interventions that are delivered at multiple levels and across varied dynamic and often complex practice settings (Gustavson et al., 2021). Thus, both the interventions and settings in which they are delivered can be characterized as complex. Implementation research therefore needs to do justice to this complexity by capturing the replicable strategies and key elements that drive implementation success within and across settings (Skivington et al., 2021).

People with lived experience of suicidality play a critical role in the co-design (Watling et al., 2020) and delivery (Schlichthorst et al., 2020) of suicide prevention programs and interventions. They are therefore important key stakeholders to consult in implementation processes and can in many ways be regarded as the ultimate arbiters of implementation success. Since lived experience co-design and co-production increasingly reflect the ethos of care in suicide prevention, implementation research will equally benefit from adopting co-design principles and from broadening traditional sources of evidence in determining what counts as quality care or implementation success.

In suicide prevention, as in other fields, low-value care and ineffective interventions should ideally be de-implemented or substituted with evidence-based practices and more effective interventions (Nilsen et al., 2020; Patey et al., 2021). Implementation research can therefore not only contribute to identifying and closing evidence-practice gaps, but it may also provide the means to inform the necessary de-implementation and prudent substitution of low-value care with more effective care (Grimshaw et al., 2020).

\section{Hybrid Study Designs: Capturing Effectiveness and Implementation} Outcomes

The choice of appropriate study designs is crucial to advancing implementation research and practice in suicide prevention. Hybrid effectiveness-implementation designs (Curran et al., 2012; Landes et al., 2019) show particular promise for expanding the evidence base regarding effective interventions and their successful implementation. A key advantage of hybrid study designs is that these enable the simultaneous examination of effectiveness and implementation outcomes, while varying in the degree to which 
emphasis is placed on each. The primary focus of a Type 1 hybrid design is on examining intervention effectiveness, while also partly exploring implementability. A Type 2 hybrid design is dually focused on examining the effectiveness of both the intervention and the implementation strategies during a hybrid trial. A Type 3 hybrid design is primarily focused on evaluating implementation strategies, while some information on effectiveness may also be gathered (Beidas et al., 2021).

Randomized implementation trials can be time- and resource-intensive and thus may not always be feasible. Nevertheless, recent guidance suggests that such designs can be warranted whenever three conditions are met (i.e., there is an effective intervention; a known evidencepractice gap; and equipoise regarding the effects of an implementation strategy; Wolfenden et al., 2021).

Well-trained scientists who understand the importance of research design for answering questions about clinical intervention outcomes and effectiveness do not always apply this same level of rigor to answering questions about implementation effectiveness. Hence, a future challenge for research training is to develop dual capability and expertise for implementation and intervention research.

\section{Contexts and Applications (Multilevel Interventions)}

In principle, implementation science approaches are applicable to any type of suicide prevention intervention, modality, context, setting, or target group. In the following, we briefly explore key considerations for implementation practice and research using examples of multilevel suicide prevention interventions. There is strong support for implementation of a combination of evidence-based interventions in suicide prevention (Mann et al., 2021; van der Feltz-Cornelis et al., 2011) due to their synergistic impact (Harris et al., 2016). However, multilevel interventions are also more complex to evaluate and implement (Mann et al., 2021). Three examples of comprehensive multilevel interventions implemented in diverse contexts are discussed here (see Table E1 in Electronic Supplementary Material 1 [ESM 1]).

Possibly the most widely known is the European Alliance Against Depression (Hegerl et al., 2008), targeting depression and suicidal behavior. The program involved four community-based interventions, which were effective in reducing suicidal behavior. Based on this model, the Optimizing Suicide Prevention Programs and Their Implementation in Europe (OSPI) project was implemented in Ireland, Portugal, Hungary, and Germany. The OSPI project was enhanced by an additional evidence-based, standard- ized intervention, implemented simultaneously in the four regions. The enhanced intervention was evaluated using a prospective controlled design, to assess composite suicidal acts (primary outcome), along with a process evaluation to monitor implementation of interventions within different regions with varying organizational and healthcare contexts (Hegerl et al., 2009). Analysis of local contexts in the participating countries revealed that engaging a formal, local group of multiple stakeholders had a substantial impact on OSPI implementation activities. Identifying and building on existing working relationships and networks to promote information sharing, participation in programs, and collaborative problem solving was found to be helpful in the countries where all interventions were implemented optimally (Harris et al., 2013; Harris et al., 2016).

Utilizing the implementation efforts and learnings in Europe, another multicomponent intervention, the Suicide Prevention and Implementation Research Initiative (SPIRIT), is currently in progress in Gujarat, Western India. The project comprises a comprehensive suicide prevention program with three evidence-based interventions tested in the context of a cluster-randomized trial (Pathare et al., 2020). The study objective is to evaluate the reach, adoption, effectiveness, and economic costs of an integrated suicide prevention program in a rural, low-resource setting. In its formative stages, strategies such as developing an implementation blueprint consisting of timeframe, milestones, and measures of quality and progress along with comprehensive knowledge of local community needs were developed. These processes are essential in planning and guiding implementation efforts on the ground. Before introducing the intervention to the community, laying the groundwork by interacting to build a coalition with local stakeholders, adapting program implementation materials to suit local needs, and garnering support of the local governing structures as partners have been identified as crucial processes for stakeholder buy-in and optimal implementation of all interventions (Pathare et al., 2020).

While it is important to build on learnings from other projects, implementation and development of the suicide prevention interventions need to be tailored to the local culture. In a culturally driven multilevel intervention, understanding the history of the community and the social processes involved in decision-making have been highlighted as key implementation processes in the context of the Qungasvik program (Rasmus et al., 2014). The Qungasvik is a multilevel intervention employing a Yup'ik Alaskan Native approach to suicide and alcohol abuse prevention. It is a community-initiated and community-driven process with an emphasis on enhancing protective factors at the community, family, and individual levels. Multiple intervention activities or modules are described in a manual including brief descriptions of the intervention setting 
Table 1. Key actions to advance implementation research and practice in suicide prevention

\begin{tabular}{|c|c|c|}
\hline Researchers & Practitioners and service providers & Policy makers \\
\hline \multicolumn{3}{|c|}{ Keep up to date with the evidence on current best practice and effective suicide prevention interventions } \\
\hline $\begin{array}{l}\text { Identify and appraise critical evidence- } \\
\text { practice and quality-of-care gaps in suicide } \\
\text { prevention }\end{array}$ & $\begin{array}{l}\text { Use implementation science frameworks } \\
\text { and evidence to inform the selection of } \\
\text { implementation strategies when rolling } \\
\text { out new interventions or fostering practice } \\
\text { change }\end{array}$ & $\begin{array}{l}\text { Policy makers and funding bodies to explicitly } \\
\text { embed implementation research within guid- } \\
\text { ance for routine program rollout, evaluation, } \\
\text { and monitoring }\end{array}$ \\
\hline $\begin{array}{l}\text { Adopt implementation science frameworks } \\
\text { and research designs to conduct systematic } \\
\text { research to address gaps }\end{array}$ & $\begin{array}{l}\text { Routinely monitor and evaluate intervention } \\
\text { effectiveness and implementation success }\end{array}$ & $\begin{array}{l}\text { Facilitate knowledge transfer about effective } \\
\text { implementation strategies within the suicide } \\
\text { prevention sector }\end{array}$ \\
\hline $\begin{array}{l}\text { Establish the evidence base for effec- } \\
\text { tive implementation strategies in suicide } \\
\text { prevention }\end{array}$ & $\begin{array}{l}\text { Harness practice wisdom and collaborate } \\
\text { with researchers in developing the evidence } \\
\text { for effective implementation }\end{array}$ & $\begin{array}{l}\text { Develop evidence-based policy and initiatives } \\
\text { to address policy-practice gaps }\end{array}$ \\
\hline \multicolumn{3}{|c|}{ Actively collaborate with key stakeholders to inform and foster effective implementation in suicide prevention } \\
\hline
\end{tabular}

along with steps for implementation of the activities for enhancing protective factors. Their focus is to create localized practices that are "owned" by and customized to each community setting. Working with the community elders, local leaders, recognizing strengths at a local level, and developing a collaborative communication and implementation plan with the local community are essential for successful implementation (Rasmus et al., 2014).

All three multilevel interventions employed designated implementation strategies in practice, which were either examined through process evaluations as part of larger intervention trials or co-designed with key stakeholders right from the start. Yet, while such processes can yield valuable insights to facilitate the future implementation of interventions, most implementation-focused research in suicide prevention has so far stopped short of explicitly adopting implementation science frameworks or testing implementation strategies.

\section{Advancing Future Implementation Research and Practice}

The WHO Live Life implementation guide (WHO, 2021) delivers the global policy impetus and practical guidance for countries to strengthen the implementation of evidence-based suicide prevention interventions. In concert with this, future implementation research should systematically build the evidence for effective implementation strategies that facilitate the dissemination, adaptation, scaling up, and sustainability of evidence-based interventions and support practice change. To this end, Table 1 highlights recommended key actions for stakeholders to advance future implementation research, knowledge, and practice in suicide prevention.

\section{Conclusion}

The suicide prevention field has a rich tradition of developing and delivering interventions across varied and complex settings. As the evidence for effective interventions consolidate, we require a systematic approach to understand and address existing evidence-practice and quality-of-care gaps and ensure the efficient translation of interventions into practice. Implementation science provides the tools and frameworks to advance implementation research and practice in the field with a view to ensuring that evidence-based interventions result in the quality of care that optimally benefits people at risk of suicide.

\section{Electronic Supplementary Material}

The electronic supplementary material is available with the online version of the article at https://doi.org/ 10.1027/0227-5910/a000846

ESM 1. Examples of multilevel interventions (implementation strategies and research approaches)

\section{References}

Bauer, M. S., Damschroder, L., Hagedorn, H., Smith, J., \& Kilbourne, A. M. (2015). An introduction to implementation science for the non-specialist. BMC Psychology, 3(1), 32. https://doi. org/10.1186/s40359-015-0089-9

Beidas, R. S., Ahmedani, B. K., Linn, K. A., Marcus, S. C., Johnson, C., Maye, M., Westphal, J., Wright, L., Beck, A. L., Buttenheim, A. M., Daley, M. F., Davis, M., Elias, M. E., Jager-Hyman, S., Hoskins, K., Lieberman, A., McArdle, B., Ritzwoller, D. P., Small, D. S., Wolk, C. B., Williams, N. J., \& Boggs, J. M. (2021). Study protocol for a type 
III hybrid effectiveness-implementation trial of strategies to implement firearm safety promotion as a universal suicide prevention strategy in pediatric primary care. Implementation Science, 16(1), 89. https://doi.org/10.1186/s13012-021-01154-8

Cane, J., O'Connor, D., \& Michie, S. (2012). Validation of the theoretical domains framework for use in behaviour change and implementation research. Implementation Science, 7(17), 37. https:// doi.org/10.1186/1748-5908-7-37

Curran, G. M., Bauer, M., Mittman, B., Pyne, J. M., \& Stetler, C. (2012). Effectiveness-implementation hybrid designs combining elements of clinical effectiveness and implementation research to enhance public health impact. Medical Care, 50(3), 217-226. https://doi.org/10.1097/MLR.0b013e3182408812

Damschroder, L. J., Aron, D. C., Keith, R. E., Kirsh, S. R., Alexander, J. A., \& Lowery, J. C. (2009). Fostering implementation of health services research findings into practice: A consolidated framework for advancing implementation science. Implementation Science, 4(15), 50. https://doi.org/10.1186/1748-5908-4-50

French, S. D., Green, S. E., O'Connor, D. A., McKenzie, J. E., Francis, J. J., Michie, S., Buchbinder, R., Schattner, P., Spike, N., \& Grimshaw, J. M. (2012). Developing theory-informed behaviour change interventions to implement evidence into practice: A systematic approach using the Theoretical Domains Framework. Implementation Science, 7(8), 38. https://doi.org/ 10.1186/1748-5908-7-38

Graham, I. D., Logan, J., Harrison, M. B., Straus, S. E., Tetroe, J., Caswell, W., \& Robinson, N. (2006). Lost in knowledge translation: Time for a map? Journal of Continuing Education in the Health Professions, 26(1), 13-24. https://doi.org/10.1002/chp.47

Grimshaw, J. M., Patey, A. M., Kirkham, K. R., Hall, A., Dowling, S. K., Rodondi, N., Ellen, M., Kool, T., van Dulmen, S. A., Kerr, E. A., Linklater, S., Levinson, W., \& Bhatia, R. S. (2020). De-implementing wisely: Developing the evidence base to reduce low-value care. BMJ Quality \& Safety, 29(5), 409-417. https://doi.org/10.1136/ bmjqs-2019-010060

Gustavson, A. M., Linskens, E. J., Sayer, N. A., Murdoch, M., Venables, N., MacDonald, R., McKenzie, L., Ullman, K. E., Wilt, T. J., \& Sultan, S. (2021). The intersection of implementation science and community-based suicide prevention research: Opportunities to advance the field. Journal of Affective Disorders, 290, 237-239. https://doi.org/10.1016/j.jad.2021.04.043

Harris, F. M., Maxwell, M., O'Connor, R., Coyne, J. C., Arensman, E., Coffey, C., Koburger, N., Gusmão, R., Costa, S., Székely, A., Cserhati, Z., McDaid, D., van Audenhove, C., \& Hegerl, U. (2016). Exploring synergistic interactions and catalysts in complex interventions: Longitudinal, mixed methods case studies of an optimised multi-level suicide prevention intervention in four European countries (Ospi-Europe). BMC Public Health, 16(1), 268. https://doi.org/10.1186/s12889-016-2942-z

Harris, F. M., Maxwell, M., O'Connor, R. C., Coyne, J., Arensman, E., Székely, A., Gusmão, R., Coffey, C., Costa, S., Cserháti, Z., Koburger, N., van Audenhove, C., McDaid, D., Maloney, J., Värnik, P., \& Hegerl, U. (2013). Developing social capital in implementing a complex intervention: A process evaluation of the early implementation of a suicide prevention intervention in four European countries. BMC Public Health, 13(1), 158. https://doi. org/10.1186/1471-2458-13-158

Hegerl, U., Wittmann, M., Arensman, E., van Audenhove, C., Bouleau, J.-H., van der Feltz-Cornelis, C., Gusmao, R., Kopp, M., Löhr, C., Maxwell, M., Meise, U., Mirjanic, M., Oskarsson, H., Perez Sola, V., Pull, C., Pycha, R., Ricka, R., Tuulari, J., Värnik, A., \& Pfeiffer-Gerschel, T. (2008). The 'European Alliance Against Depression (EAAD)': A multifaceted, community-based action programme against depression and suicidality. World Journal of Biological Psychiatry, 9(1), 51-58. https://doi.org/ 10.1080/15622970701216681
Hegerl, U., Wittenburg, L., Arensman, E., Van Audenhove, C., Coyne, J. C., McDaid, D., Feltz-Cornelis, C. M., van der, Gusmão, R., Kopp, M., Maxwell, M., Meise, U., Roskar, S., Sarchiapone, M., Schmidtke, A., Värnik, A., \& Bramesfeld, A. (2009). Optimizing suicide prevention programs and their implementation in Europe (OSPI Europe): An evidence-based multi-level approach. BMC Public Health, 9(1), 428. https://doi.org/10.1186/14712458-9-428

Kapur, N., Gorman, L. S., Quinlivan, L., \& Webb, R. T. (2021). Mental health services: Quality, safety and suicide. BMJ Quality \& Safety. Advance online publication. https://doi.org/10.1136/ bmjqs-2021-013532

Landes, S. J., McBain, S. A., \& Curran, G. M. (2019). An introduction to effectiveness-implementation hybrid designs. Psychiatry Research, 280, 112513. https://doi.org/10.1016/j.psychres. 2019.112513

Levinson, W., Kallewaard, M., Bhatia, R. S., Wolfson, D., Shortt, S., \& Kerr, E. A. (2015). 'Choosing Wisely': A growing international campaign. BMJ Quality \& Safety, 24(2), 167-174. https://doi. org/10.1136/bmjqs-2014-003821

Mann, J.J., Michel, C. A., \& Auerbach, R. P. (2021). Improving suicide prevention through evidence-based strategies: A systematic review. American Journal of Psychiatry, 178(7), 611-624. https:// doi.org/10.1176/appi.ajp.2020.20060864

Michie, S., Johnston, M., Abraham, C., Lawton, R., Parker, D., Walker, A., \& Psychological Theory Group. (2005). Making psychological theory useful for implementing evidence based practice: A consensus approach. Quality \& Safety in Health Care, 14(1), 26-33. https://doi.org/10.1136/qshc.2004.011155

Michie, S., Richardson, M., Johnston, M., Abraham, C., Francis, J., Hardeman, W., Eccles, M. P., Cane, J., \& Wood, C. E. (2013). The Behavior Change Technique Taxonomy (v1) of 93 hierarchically clustered techniques: Building an international consensus for the reporting of behavior change interventions. Annals of Behavioral Medicine, 46(1), 81-95. https://doi.org/10.1007/ s12160-013-9486-6

Nilsen, P. (2015). Making sense of implementation theories, models and frameworks. Implementation Science, 10(13), 53. https:// doi.org/10.1186/s13012-015-0242-0

Nilsen, P., Ingvarsson, S., Hasson, H., von Thiele Schwarz, U., \& Augustsson, H. (2020). Theories, models, and frameworks for de-implementation of low-value care:A scoping review of the literature. Implementation Research and Practice, 1, 2633489520953762. https://doi.org/10.1177/2633489520953762

Patey, A., Grimshaw, J. M., Hurt, C., \& Francis, J. J. (2021). Changing behaviour, 'more or less': Do implementation and de-implementation interventions include different behaviour change techniques? Implementation Science, 16, 20. https://doi.org/ 10.1186/s13012-021-01089-0

Pathare, S., Shields-Zeeman, L., Vijayakumar, L., Pandit, D., Nardodkar, R., Chatterjee, S., Kalha, J., Krishnamoorthy, S., Jain, N., Kapoor, A., Shahjahan, M., Chauhan, A., \& Smit, F. (2020). Evaluation of the SPIRIT Integrated Suicide Prevention Programme: Study protocol for a cluster-randomised controlled trial in rural Gujarat, India. Trials, 21(1), 572. https://doi.org/10.1186/ s13063-020-04472-2

Pirkis, J., \& Hawton, K. (2021). Evaluating suicide prevention activities. In K. Kõlves, M. Sisask, P. Värnik, A. Värnik, \& D. De Leo (Eds.), Advancing suicide research (pp. 225-236). Hogrefe.

Powell, B. J., Proctor, E. K., \& Glass, J. E. (2014). A systematic review of strategies for implementing empirically supported mental health interventions. Research on Social Work Practice, 24(2), 192-212. https://doi.org/10.1177/1049731513505778

Powell, B. J., Waltz, T. J., Chinman, M. J., Damschroder, L. J., Smith, J. L., Matthieu, M. M., Proctor, E. K., \& Kirchner, J. E. (2015). A refined compilation of implementation strategies: Results 
from the Expert Recommendations for Implementing Change (ERIC) project. Implementation Science, 10(14), 21. https://doi. org/10.1186/s13012-015-0209-1

Presseau, J., McCleary, N., Lorencatto, F., Patey, A. M., Grimshaw, J. M., \& Francis, J. J. (2019). Action, actor, context, target, time (AACTT): A framework for specifying behaviour. Implementation Science, 14(1), 102. https://doi.org/10.1186/s13012-0190951-x

Proctor, E. K., Landsverk, J., Aarons, G., Chambers, D., Glisson, C., \& Mittman, B. (2009). Implementation research in mental health services: An emerging science with conceptual, methodologi$\mathrm{cal}$, and training challenges. Administration and Policy in Mental Health and Mental Health Services Research, 36(1), 24-34. https://doi.org/10.1007/s10488-008-0197-4

Proctor, E., Silmere, H., Raghavan, R., Hovmand, P., Aarons, G., Bunger, A., Griffey, R., \& Hensley, M. (2011). Outcomes for implementation research: Conceptual distinctions, measurement challenges, and research agenda. Administration and Policy in Mental Health and Mental Health Services Research, 38(2), 6576. https://doi.org/10.1007/s10488-010-0319-7

Proctor, E. K., Powell, B. J., \& McMillen, J. C. (2013). Implementation strategies: Recommendations for specifying and reporting. Implementation Science, 8(1), 139. https://doi.org/10.1186/17485908-8-139

Rasmus, S. M., Charles, B., \& Mohatt, G. V. (2014). Creating Qungasvik (A Yup'ik intervention "toolbox"): Case examples from a community-developed and culturally-driven intervention. American Journal of Community Psychology, 54(1-2), 140-152. https://doi. org/10.1007/s10464-014-9651-5

Schlichthorst, M., Ozols, I., Reifels, L., Morgan, A. (2020). Lived experience peer support programs for suicide prevention: A systematic scoping review. International Journal of Mental Health Systems, 14, 65. https://doi.org/10.1186/s13033-020-00396-1

Schuster, M. A., McGlynn, E. A., \& Brook, R. H. (1998). How good is the quality of health care in the United States? Milbank Quarterly, 76(4), 517. https://doi.org/10.1111/1468-0009.00105

Shrank, W. H., Rogstad, T. L., \& Parekh, N. (2019). Waste in the US health care system: Estimated costs and potential for savings. JAMA, 322(15), 1501-1509. https://doi.org/10.1001/jama. 2019.13978

Skivington, K., Matthews, L., Simpson, S. A., Craig, P., Baird, J., Blazeby, J. M., Boyd, K. A., Craig, N., French, D. P., Mclntosh, E., Petticrew, M., Rycroft-Malone, J., White, M., \& Moore, L. (2021). A new framework for developing and evaluating complex interventions: Update of Medical Research Council guidance. British Medical Journal, 374(11), n2061. https://doi.org/10.1136/bmj. n2061

Tabak, R. G., Khoong, E. C., Chambers, D. A., \& Brownson, R. C. (2012). Bridging research and practice models for dissemination and implementation research. American Journal of Preventive Medicine, 43(3), 337-350. https://doi.org/10.1016/j.ame pre.2012.05.024

van der Feltz-Cornelis, C. M., Sarchiapone, M., Postuvan, V., Volker, D., Roskar, S., Grum, A. T., Carli, V., McDaid, D., O'Connor, R., Maxwell, M., Ibelshäuser, A., Van Audenhove, C., Scheerder, G., Sisask, M., Gusmão, R., \& Hegerl, U. (2011). Best practice elements of multilevel suicide prevention strategies. Crisis, 32(6), 319-333. https://doi.org/10.1027/0227-5910/a000109

Watling, D., Preece, M., Hawgood, J., Bloomfield, S., \& Kõlves, K. (2020). Developing an intervention for suicide prevention: A rapid review of lived experience involvement. Archives of Suicide Research. Advance online publication. https://doi.org/10. 1080/13811118.2020.1833799

While, D., Bickley, H., Roscoe, A., Windfuhr, K., Rahman, S., Shaw, J., Appleby, L., \& Kapur, N. (2012). Implementation of mental health service recommendations in England and Wales and suicide rates, 1997-2006: A cross-sectional and before-and-after observational study. Lancet, 379(9820), 1005-1012. https://doi. org/10.1016/s0140-6736(11)61712-1

Wolfenden, L., Foy, R., Presseau, J., Grimshaw, J. M., Ivers, N. M., Powell, B. J., Taljaard, M., Wiggers, J., Sutherland, R., Nathan, N., Williams, C. M., Kingsland, M., Milat, A., Hodder, R. K., \& Yoong, S. L. (2021). Designing and undertaking randomised implementation trials: Guide for researchers. British Medical Journal, 372(14), m3721. https://doi.org/10.1136/bmj.m3721

World Health Organization. (2021). Live Life: An implementation guide for suicide prevention in countries. https://apps.who.int/ iris/handle/10665/341726

Zbukvic, I. C., Mok, K., McGillivray, L., Chen, N. A., Shand, F. L., \& Torok, M. H. (2020). Short report: Understanding the process of multilevel suicide prevention research trials. Evaluation and Program Planning, 82(4), 101850. https://doi.org/10.1016/j. evalprogplan.2020.101850

Published online January 12, 2022

\section{Funding}

This work was conducted as part of the LIFEWAYS Project with funding support from the Australian Government Department of Health through the National Suicide Prevention Leadership and Support Program.

\section{Lennart Reifels}

Centre for Mental Health

The University of Melbourne

207 Bouverie Street

Carlton, VIC, 3010

Australia

l.reifels@unimelb.edu.au

Lennart Reifels, PhD, is a senior research fellow at the Centre for Mental Health, The University of Melbourne, Australia, who coordinates the LIFEWAYS Project: Leading Research Into Suicide Prevention (previously known as the National Leadership in Suicide Prevention Research Project). His key research areas include suicide prevention, population mental health, and disaster risk reduction.

Sadhvi Krishnamoorthy is a PhD candidate at the Australian Institute for Suicide Research and Prevention, School of Applied Psychology, Griffith University, Australia. She has had experience of working with large-scale, community-based multilevel implementation programs in low-resource settings and is interested in understanding the mechanisms involved in translation of research into practice.

Kairi Kõlves, PhD, is professor at the Australian Institute for Suicide Research and Prevention and director of the WHO Collaborating Centre for Research and Training in Suicide Prevention at Griffith University, Australia. She is well known for her work in epidemiology of suicidal behaviors and suicide bereavement.

Jillian Francis, PhD, is professor of implementation science at the Melbourne School of Health Sciences, Australia. She is known internationally for advancing theoretical and methodological developments in the field of behavioral implementation science across a wide range of clinical settings. 